\title{
References
}

1 Bonow RO, Bacharach SL, Green MV, et al. Impaired left ventricular diastolic filling in patients with coronary artery disease: assessment with radionuclide angiography. Circulation 1981; 64: 315-23.

2 Reduto LA, Wickemeyer WJ, Young JB, et al. Left ventricular diastolic performance at rest and during exercise in patients with coronary artery disease. Assessment with first-pass radionuclide angiography. Circulation 1981; 63: 1228-37.

\section{Analysis of circadian blood pressure rhythms}

Sir,

We read with interest the observation by Davies et al (1984; 52: 93-8) on the circadian rhythm of blood pressure. The authors state that Millar-Craig et al reported a second peak of blood pressure in the early evening. ${ }^{1}$ We consider that this is not a correct citation, as Millar-Craig et al reported that ". . . blood pressure fell progressively during the day and rose in the early hours of the morning."

Davies et al mention the difficulties in quantifying variations in the blood pressure. Some of the basic work on rhythmic blood pressure changes (summarised in ${ }^{2}$ ) deals with the problems of recording, reproducibility, and analysis of blood pressure patterns. Using cosinor analysis, first introduced by Halberg et $\mathrm{al}^{3}$ might improve the accuracy of analysis. It provides an exact calculation of rhythm variables such as mesor, amplitude, and acrophase of circadian rhythmic changes. ${ }^{4-6}$ It would be interesting to evaluate the carefully documented data of Davies et al by cosinor analysis. We wonder whether this method of analysis would confirm the reported two hour difference between the nadir of the paced group and the control group.

The authors also point out that the amplitude of the cirdacian pattern was lower in the paced than in the hypertensive group. Judging from the data in Fig. 1 of their article this seems not unlikely. Quantitative evaluation of the amplitudes, however, is not reported but might be done by cosinor analysis. Furthermore, cosinor analysis might allow a better comparison of circadian heart rate and blood pressure variations.

Alexander L Gerbes, *

Ekkehard Haen, $t$

Bernhard Arbogast,

^ Medizinische Klinik II,

Klinikum Grosshadern der Universität Munchen.

†Institute of Pharmacology,

Universität Munchen.

¥Bavarian Reinsurance Company, D-8000 Munich 22,

Federal Republic of Germany.
3 Mancini GBJ, Slutsky RA, Norris SL, Bhargava V, Ashburn WL, Higgins CB. Radionuclide analysis of peak filling rate, filling fraction and time to peak filling rate. Response to supine bicycle exercise in normal subjects and patients with coronary disease. Am $\mathcal{F}$ Cardiol 1981; 51: 43-51.

4 Nichols AB, Strauss HW, Moore RH, et al. Acute changes in cardiopulmonary blood volume during upright exercise stress testing in patients with coronary heart disease. Circulation 1979; 60: 520-30.

\section{References}

1 Millar-Craig MW, Bishop CN, Raftery EB. Circadian variation of blood-pressure. Lancet 1978; i: 795-7.

2 Halberg F. Quo vadis basic and clinical chronobiology: promise for health maintenance. Am $\mathcal{F}$ Anat 1983; 168: 543-94.

3 Halberg F, Tong YL, Johnson EA. Circadian system phase -an aspect of temporal morphology; procedures and illustrative examples. In: Von Mayersbach $\mathrm{H}$, ed. The cellular aspect of biorhythms. Berlin: Springer, 1967: 20-48.

4 Bingham C, Arbogast B, Guillaume GC, Lee JK, Halberg $F$. Inferential statistical methods for estimating and comparing cosinor parameters. Chronobiologia 1982; 11: 397-439.

5 Gerbes AL, Arbogast B, Schick P, Messerschmidt $O$. Acute radiation injury of mice and the influence of sudden time shift. Radiat Res 1984; 99: 285-93.

6 Haen E, Halberg F, Cornelissen G. Cortisol marker rhythmometry in pediatrics and clinical pharmacology. Annual Review of Chronopharmacology 1984, in press.

This letter was shown to the authors, who reply as follows:

Sir,

We thank Drs Gerbes et al for their interest in our paper on circadian rhythms of blood pressure in paced patients. They correctly cite our original description of the broad 24 hour pattern of blood pressure ${ }^{1}$; however, most of our data on closer inspection showed a subsidiary late afternoon rise of lower amplitude than that seen after waking. This is visible in Figs. 1 and 3 of the original publication. ${ }^{1}$

The problems inherent in describing ambulatory intra-arterial blood pressure patterns have been recognised by several groups of workers. We find it difficult to accept that Halberg's cosinor analysis would be able to provide sufficient accuracy in this case. As we understand it, the technique consists of fitting a single 24 hour cosine curve to the data using the method of least squares. Variables such as the amplitude, mesor (average value), and acrophase (tim- 
ing of the peak relative to an arbitrary time origin) are then measured from the fitted curve. The pattern of blood pressure is not symmetrical within a 24 hour cycle; for example, a single cosine function would be a very poor fit to the systolic data in Fig. 1 of our paper. This observation appears to be confirmed by the work of Murnaghan et al in their study of blood pressure in pregnancy. ${ }^{2}$ The single cosinor technique failed to give sufficient resolution to describe other than gross features of the blood pressure patterns. Walsh and Goldberg also found that significant components were present at higher frequencies. ${ }^{3}$ Detailed studies by Sayers ${ }^{4}$ indicate the presence of several concurrent patterns, posing severe problems in any detailed statistical analysis across patients. More recently, the same group has suggested a set of procedures for pattern analysis of these records, relying more on measurements from each record than on a priori models. 5 These procedures are at present being applied to blood pressure data from a variety of sources.

In active untreated subjects the timing of the acrophase must be heavily dependent on the time of waking since this is the event which has the greatest effect on blood pressure. This would tend to place the acrophase at approximately 14 hours before waking - that is, at 1800 or so, and this has been the finding of several workers. ${ }^{36}$ It is hard to see how this would provide any illumination of our observed shifts in the nadir of blood pressure at around 0100-0300. For critical studies we now compile our data relative to waking time as well as to absolute clock time.

We are therefore unconvinced that cosinor analysis would clarify our observations of ambulatory intra- arterial blood pressure unless applied in a complex form taking account of many pattern features and frequencies, in which case conventional Fourier analysis seems to offer more possibilities.

E B Raftery,

P M M Cashman,

Departments of Cardiology and Bioengineering,

Northwick Park Hospital,

Harrow, Middlesex HAl 3UJ.

\section{References}

1 Millar Craig MW, Bishop CN, Raftery EB. Circadian variation of blood pressure. Lancet 1978; i: 795-7.

2 Murnaghan GA, Mitchell RH, Ruff SC. Blood pressure rhythms in normotensive and pre-eclamptic pregnancy. In: Stott FD, Raftery EB, Goulding L, eds. Proceedings of ISAM 1979. London: Academic Press, 1980: 157-66.

3 Walsh JT, Goldberg AD. The analysis of prolonged records of continuous intra-arterial blood pressure-a software approach. In: Stott FD, Raftery EB, Goulding L, eds. Proceedings of ISAM 1979. London: Academic Press, 1980: 451-5.

4 Sayers BMCA. Analysis of intra-arterial blood pressure records. In: Stott FD, Raftery EB, Goulding L, eds. Proceedings of ISAM 1979. London: Academic Press, 1980: 513-35.

5 Sayers BMcA, Cicchiello LR, Raftery EB, Mann S, Green HL. The assessment of continuous ambulatory blood pressure records. Med Inf (Lond) 1982; 7: 93-108.

6 Halberg F. Quo vadis basic and clinical chronobiology: promise for health maintenance. Am $\mathcal{J}$ Anat 1983; 168: 543-94.

\section{Delayed recovery of left ventricular function after anti- thyroid treatment}

Sir,

Forfar et al (1984; 52: 215-22) suggest that in hyperthyroidism left ventricular function is reversibly depressed. Their conclusions are based on haemodynamic measurements performed on 15 hyperthyroid subjects before and during isometric exercise, and those measurements were repeated after the subjects had been rendered euthyroid. The authors stress that hyperthyroidism involves changes intrinsic not only to the heart itself but also to the peripheral circulation. They assume, however, that the performance of a standardised isometric exercise task produced the same changes in the peripheral circulation in both hyperthyroid and euthyroid states and, therefore, that exercise caused the same changes.

in cardiac loading before and after the subjects had... Thestit would appear that peripheral resistance is been treated for their thyrotoxicosis. Nevertheless, as shown in the Table below, using data taken from their own paper it may be calculated that isometric exercise actually caused directionally opposite changes in peripheral vascular resistance during the thyrotoxic and euthyroid states. Peripheral vascular resistance is a major determinant of the impedance offered to the outflow of blood from the left ventricle. In the study of Forfar et al the thyrotoxic heart, faced with an increased peripheral resistance during isometric exercise, did not function as well as it did at rest. In contrast, the euthyroid heart experienced a large reduction in calculated peripheral vascular resistance during isometric exercise and showed no deterioration in function. 